\title{
Merleau-Ponty, Deleuze, and the Question Singular: What Marks the Difference between Humans and Animals?
}

\author{
Arsalan Memon \\ SUNY Stony Brook
}

Abstract: What marks the difference between humans and animals? At what point does a human become an animal and vice versa? What is the difference between human flesh and animal meat and reversibly, between human meat and animal flesh? Where is the line to be drawn between them, if possible? This paper seeks to problematize and rethink the long-established difference between humans and animals via Merleau-Ponty's notions of flesh and animality and Deleuze's notions of meat and the zone of indiscerniblility, as they are presented, respectively, in The Visible and the Invisible and in the second and third courses on nature in Nature: Course Notes from the College de France - "Animality, the Human Body, and the Passage to Culture" and "Nature and Logos: The Human Body"and in the fourth chapter, "Body, Meat, and Spirit: BecomingAnimal," of the book, Francis Bacon: The Logic of Sensation. In addition, Francis Bacon's paintings are used to illustrate the ambiguity and indiscerniblility between the human flesh and the animal meat. Suffice it to say, the clear-cut traditional distinction between a human animal and a non-human animal is called into question and is rethought through their corporeity rather than their intrinsic mental faculties.

The flesh is not matter, is not mind, is not substance.

Maurice Merleau-Ponty, The Visible and the Invisible

We study the human through its body in order to see it emerge as different from the animal, not by the addition of reason, but rather, in short, in the Ineinander with the animal (strange anticipations or caricatures of the human in the animal)...

Maurice Merleau-Ponty, Nature: Course Notes from the Collège de France

Auslegung, Vol. 28, No. 2 
Meat is the state of the body in which flesh and bone confront each other locally rather than being composed structurally.... In meat, the flesh seems to descend from the bones, while the bones rise up from the flesh. ... Meat is the common zone of man and the beast, their zone of indiscernibility...

Gilles Deleuze,

Francis Bacon: The Logic of Sensation

\section{The Issue}

Humans are rational animals and all non-humans are non-rational animals. This is not the argument of this essay; it could well serve as one, but it will not. It was an argument since the time of Aristotle and also, it was the beginning of the mark of difference between humans and animals. And here it is a beginning of this paper with the opening epigraphs-by Maurice Merleau-Ponty and Gilles Deleuze - reflecting on the ambiguity and indiscernibility between humans and animals, on the one hand and flesh and meat, on the other. Since the birth of philosophy, a wedge has been driven between humans and animals. According to the western philosophical tradition, humans are beings that are not animals in the strictest sense of the word. But then the question that follows or should follow from such a claim: If humans are not animals, then what are they? How are they to be distinguished from animals? What marks the difference between the humans and the animals? Is the mark of difference on either side of the difference itself? It is these questions that have led me to write this paper on Merleau-Ponty and Deleuze on the theme of animal difference.

The goal of this paper is to problematize and rethink the difference between humans and animals through Merleau-Ponty's notions of flesh and animality and Deleuze's notions of meat and the zone of indiscerniblility. To accomplish the goal of this paper, I begin by presenting an overview of Merleau-Ponty's negative ontology of flesh as it is presented in his last and unfinished book, The Visible and the Invisible. This, as we will see, leads us into comparing and contrasting Merleau-Ponty's notion of flesh with Deleuze's notion of flesh and meat. Then I present Deleuze's notion of meat, which is articulated in the fourth chapter, "Body, Meat, and Spirit: Becoming-Animal," of his book, Francis Bacon: The 
Logic of Sensation. Five paintings of Francis Bacon are used to illustrate Deleuze's notion of meat more lucidly, the paintings thus follows: Three Studies of George Dyer (1966), Study for Head of Lucian Freud (1967), Three Studies for Portrait of Isabel Rawsthorne (1968), Three Studies for Henrietta Moraes (1969), and Portrait of Michel Leiris (1976).

Next, I explain the textual gap that lies between MerleauPonty's last book, The Visible and the Invisible and his last three courses on nature and animal difference, which are compiled in the book entitled, Nature: Course Notes from the College de France. The reason for such an explanation lies in showing the development of Merleau-Ponty's later thought. After that, I give an extensive account of Merleau-Ponty's notion of animality, which is discussed in the second and third course, respectively, "Animality, the Human Body, and the Passage to Culture" and "Nature and Logos: The Human Body." Lastly, the convergences and divergences between Merleau-Ponty and Deleuze on the difference between (human) animal flesh and (non-human) animal meat are put forward. Having said that, let us now turn to Merleau-Ponty's ontological notion of flesh.

\section{Merleau-Ponty's Negative Ontology: Flesh, between Différences as Neither/Nor}

In his last and unfinished book, The Visible and the Invisible ${ }^{1}$, Merleau-Ponty discusses the ontological notion of flesh. First it must be pointed out that Merleau-Ponty's ontology of the flesh is a "negative philosophy" or a negative ontology (VI, 179). A negative ontology is very similar to a "negative theology" (VI, 179). Negative theology posits that God is beyond the descriptions of human language and for that reason, God's being cannot be defined positively or as what God is, but only negatively or as what God is not. Analogously, flesh can only be described or be defined negatively, however, flesh in Merleau-Ponty's ontology does not play the role that God plays in negative theology. If flesh is anything, it is not. Even though, the French word l'chair translates in English as 'flesh,' Merleau-Ponty does not mean that it is the "soft tissue of the body of a vertebrate, covering the bones and consisting mainly 
of skeletal muscle and fat" or the "surface or skin of the human body." Flesh, as it is described in the fourth chapter, "The Intertwining-The Chiasm," of the book, The Visible and the Invisible, is neither body nor mind, neither subject nor object, neither immanence nor transcendence, neither essence nor existence, neither consciousness nor object, and neither being-in-itself nor being-for-itself. To put it briefly, within the logic of neither/nor, flesh is inscribed as everything, hence, as nothing in itself.

Flesh is not a construction of the human mind. That is why it is neither another philosopheme nor like another philosopheme such as "idea," "acts of consciousness," "states of consciousness," "concept," "mind," "representation," "object," "thing," "properties," "transcendental subjectivity," "matter," "form," "image," "perception," "subject," and "meaning" (VI, 157-58; 167; 224). Further, flesh is not noçma, noçsis, or essence. As a matter of fact, it cannot be or become a philosopheme at all because " $t]$ here is no name in traditional philosophy to designate it" (VI, 139). The "it" refers to that which is termed "flesh," but any other word could be substituted for it that would better describe it because no one word exhausts or encapsulates what Merleau-Ponty labels as flesh. Merleau-Ponty presents the notion of flesh to dismantle or decenter "the objectivist ontology of the Cartesians" (VI, 183). Flesh is asubjective and nonobjective. That is, it is neither something that is subjectively constructed nor something objectively instituted, it is something between them. If there is no one word that can exhaustively and univocally define, describe, and explain what flesh is, then how can we understand what flesh is, if it is anything?

Flesh is the differentiality of all things and non-things. It is the texture, the inter-fabric in which all things and non-things are woven. It is the "common inner framework" of everything there is (VI, 227). Since it is never presented as an object or subject in the world it can never be "a representation for a mind" (VI, 139). That is to say, it has no presence, and for that reason, it can never be represented. To understand it, it must be comprehended as the chiasmic differentiality between the differences (VI, 227). For Merleau-Ponty, the differential space (l'écart) "between" all the binary oppositions is more real than either one of the opposites. It is as if "two mirrors facing one another where two indefinite series 
of images set in one another arise which belong really to neither of the two surfaces" (VI, 139). The differential space or spacing (l'écart) between the differences is the atopic place where the subject crosses over the object, where immanence crosses over transcendence, where existence crosses over essence, where consciousness crosses over the object, where being-in-itself crosses over being-for-itself, and so on. In a nutshell, it is the place of "integration-differentiation" between the chiasmic differences (VI, 233). That is to say, if flesh is anything, it is the "fields in intersection" (VI, 227). Having addressed ideas central to Merleau-Ponty's notion of flesh, I now turn to Deleuze for a discussion on meat.

\section{Deleuze, Bacon's Paintings, and the Zone of Indiscernibility of Flesh-Meat-Bones}

Deleuze revisits the issue of flesh after twenty years of the publication of The Visible and the Invisible, in the fourth chapter, "Body, Meat, and Spirit: Becoming-Animal," of his book, Francis Bacon: The Logic of Sensation ${ }^{3}$. It must be noted that a year before the publication of Francis Bacon, Deleuze takes up the question of animal difference in Chapter 10, "Becoming-Intense, Becoming-Animal, Becoming-Imperceptible...," of his book, $A$ Thousand Plateaus: Capitalism and Schizophrenia ${ }^{4}$. However in $A$ Thousand Plateaus, animal difference is understood via becoming and indiscernibility (l'indiscernabilité), whereas in Francis Bacon it is explicated through two supplemental motifs, meat and flesh. That is why, Francis Bacon is vital for our discussion.

Even though Deleuze's usage of flesh intertextually refers to Merleau-Ponty, Deleuze does not use flesh in the same way that Merleau-Ponty has used it in The Visible and the Invisible. For Deleuze, flesh is "the bodily material of the Figure" (FB, 20). His use of Figure with a capital ' $F$ ' is significant, which in French can either mean face or rhetorical figure of speech such as hyperbole, metonymy, metaphor, oxymoron, and so on. In French, you can substitute visage and figure for face, but in English, you cannot because figure does not signify a face. This is exactly what Deleuze suggests by using the word "Figure," that it is not a face, but a head, but more on the face later on. Deleuze's discussion of 
l'viande or meat begins as a form of questioning of the line of demarcation between the human and the animal. For this reason, the two words that are significant for our discussion are l'chair and $l$ 'viande. In some languages, there are two separate words for l'chair and l'viande and in some, there is only one word that embodies both terms. For instance, l'chair in English means 'flesh,' and in German, 'Fleisch,' but l'viande in English means 'meat,' and in German, 'Fleisch.' In short, the difference can be heard by two different words in French and English, whereas in German, the difference remains inaudible in one word.

Deleuze introduces the notion of "meat" to interrupt the distinctions between flesh and meat, on the one hand and humans and animals, on the other (FB, 20). But what is remarkable about Deleuze's notion of meat is that it is explicated through Francis Bacon's paintings. He uses Bacon's paintings to unfold what meat is, which ultimately leads to the blurring of the clear-cut distinction between flesh and meat and a fortiori, between the human animal and the non-human animal. As Deleuze says, "what Bacon's paintings constitute is a zone of indiscernibility (zone d'indiscernabilité) or undecidablity between man and animal. Man becomes animal..." (FB, 20). I will explain the zone of indiscernibility later on. The way in which Deleuze attempts to articulate his notion of meat through Bacon's paintings is through the distinction between the head and the face. A face is "a structured, spatial organization that conceals the head, whereas the head is dependent on the body, even if it is the point of the body, its culmination" (FB, 19). In other words, the face is the expressive aspect of the body and facial gestures and expressions are formed because of the organized arrangement of the nose, the mouth, the eyes, and the ears, whereas the head is the uppermost part of the body.

Further, Deleuze tells us that Bacon, as a portraitist, is not a painter of faces, but of heads (FB, 19). A portraitist usually captures smiles, facial expressions, or the face of the person but Bacon's paintings are paintings of "head[s] without ... face[s]" (FB, 19). To illustrate the difference between the head and the face and the notion of meat and the zone of indiscernibility more lucidly, I now turn to Bacon's paintings. There are numerous paintings of Bacon 
that articulate the distinction between the head and the face and the notion of meat, but for reasons of economy, I have only chosen the following five paintings, ${ }^{5}$ which are mentioned in Francis Bacon: Three Studies of George Dyer (1966), ${ }^{6}$ Study for Head of Lucian Freud (1967), ${ }^{7}$ Three Studies for Portrait of Isabel Rawsthorne (1968), ${ }^{8}$ Three Studies for Henrietta Moraes (1969), ${ }^{9}$ and Portrait of Michel Leiris $(1976)^{10}$. It is worthwhile to mention here that I have not followed the chronological order of the paintings in my discussion. In the painting, "Study for Head of Lucian Freud (1967)," the face seems to be effaced or skewed. It fails to look like a face. As Deleuze elaborates on the techniques behind the ef-face-ment and de-forming of the face: "In fact, the face lost its form by being subjected to the techniques of rubbing and brushing that disorganize it and make a head emerge in its place" (FB, 19). The face in the painting looks more like a lump of fleshly meat rather than just flesh. Lucian Freud's facial features such as a nose, eyes, ears, lips, or cheeks, cannot be discerned and more so, the difference between the face and the head cannot be marked. It looks like a big head or a chunk of meat, rather than a face with a head. Also, the left side of the face seems to be demented, as if the bones have sucked in the flesh.

In the painting, "Three Studies for Portrait of Isabel Rawsthorne (1968)," it seems as if the flesh is coming off of her bones. Normally, the flesh is on top of the bones, but in this painting, the obverse is being manifested. The bones predominate the flesh, while the flesh is just hanging on top of her bones, which makes it look more like meat rather than just flesh. Flesh, for that reason, according to Deleuze, is ancillary to the bones. Further, in the paintings, "Three Studies for Henrietta Moraes (1969)" and "Three Studies of George Dyer (1966)," the skeletal aspects are prevalent. Their skeletal features outline their face. The flesh no longer seems to be primary. The flesh is descending, while the skeletal features are ascending. "In meat," Deleuze goes on to say, "the flesh seems to descend from the bones, while the bones rise up from the flesh" (FB, 21). Likewise, in the painting, "Portrait of Michel Leiris (1976)," the bones are piercing through his flesh in all directions, through the nose, the cheeks, the forehead, and the chin. The face is deformed, which gives him somewhat of a meaty look. 
But what is common in all five of these paintings is the indiscernibility (l'indiscernabilité) between flesh-meatbones, between the face — the head, and between the animalthe human. The question of the limits of human flesh and animal meat is raised: where are the limits to be drawn between the nonhuman animal and the human animal? At what point does meat becomes flesh and vice versa? Their point of becoming cannot be pinpointed unambiguously. This is the zone of indiscernibility (zone d'indiscernabilité). The head emerges. The human becomes inhuman or the non-human. Flesh becomes meat. The animal becomes the human. Meat becomes flesh. The face loses its faciality. That is, the facial features become indiscernible. The distinction between the head and the face is blurred. Even the portraits of Michel Leiris and Isabel Rawsthorne strike me as very odd because portraits, normally, are suppose to enhance the picture not distort them. These portraits lack any kind of personality. There are no smiles. The faces do not even look like faces. As a matter of fact, they do not even look like humans. In short, Bacon's portraits, as mentioned previously, point to the indiscernibility between 1) the head and the face, 2) the human animal and the non-human animal, and 3) bones and flesh and meat. The question surfaces again: Where is the line to be drawn between them?

The lines cannot be drawn in a clear-cut manner (figure). For this reason, for Deleuze, human animals and non-humans animals are always in the state of becoming, as always indiscernible from one another. But this indiscernibility is manifested in Bacon's paintings because of the becoming-movement between the flesh, the meat, and the bones. It remains indiscernible whether the figures in the paintings are just meat, flesh, or bones. It is also not apparent or transparent whether the meat is on the side of the bones or on the side of the flesh. The meat lies between, on the one hand, the flesh and the bones and on the other, human animals and nonhuman animals. Meat is "the common zone of man and the beast, their zone of indiscernibility" (FB, 21). Deleuze is interested in the zone of indiscernibility (zone d'indiscernabilité) because it undoes any kind of hierarchy between, on the one hand, flesh and meat, and on the other, human animals and non-human animals. Meat interrupts the traditional reified labels, to be exact, humans 
and animals. After explaining Deleuze's notion of meat, let us now turn to Merleau-Ponty's notion of animality, which is discussed in his book, Nature. This discussion, as we will see, leads us into a better understanding of the link between Merleau-Ponty and Deleuze on the notions of meat, animality, and flesh.

\section{On the Textual Gap between Merleau-Ponty's Later Works_-Nature: Course Notes from the Collège de France and The Visible and the Invisible}

A textual remark regarding Nature and The Visible and the Invisible must be put forward before I begin discussing MerleauPonty's views on animality or meat. To talk about Merleau-Ponty vis-à-vis Deleuze's notion of meat designates a difficult task. First and foremost, Merleau-Ponty, to the best of my knowledge, never uses the French word l'viande in his three courses on nature. Secondly, these courses on nature were delivered while Merleau-Ponty was still writing The Visible and the Invisible, which he worked on even long after the courses were delivered. And it is in The Visible and the Invisible, that flesh is presented as the solution-to use a word for lack of a better word-to traditional problems, even including the problem of difference between humans and animals (VI, 250; 138). So, in a two-fold bidirectional way, The Visible and the Invisible complements Nature, while Nature supplements it. Complements it by fleshing out the ontological details that are not used and expounded in Nature and simultaneously, Nature supplements The Visible and the Invisible by adding an extra meaty dimension to it that was promised in Merleau-Ponty's last working note of the proposed plan for the book dated "March 1961": "I The visible, II Nature, III Logos" (VI, 273-74 neither the commas nor the emphasis on "II Nature" are Merleau-Ponty's).

In the same note, Merleau-Ponty says, "Hence we do not begin $a b$ homine as Descartes (the 1st part is not 'reflection') we do not take Nature in the sense of the Scholastics (the $2 \mathrm{~d}$ part is not Nature in itself, a philosophy of Nature, but a description of the man-animality intertwining)" (VI, 274; my emphasis). This proposal of "man-animality intertwining," in The 
Visible and the Invisible is precisely taken through the motif of "interanimality" of humans and animals in Nature: Course Notes from the Collège de France" (NCF, 166; 189). Nevertheless, The Visible and the Invisible seems more reliable than the course notes on nature and animality because it reveals the problems that Merleau-Ponty was preoccupied with in his last years. But since The Visible and the Invisible was never completed, we cannot and should not predict how the text would have been in its finished product, and that is why it is difficult to say whether Merleau-Ponty would have return to the problem of animal difference through the notion of animality or flesh. Maybe he would have incorporated both in his ontology, since they both complement and supplement each other through and through. It remains indecidable. Regardless of the textual gap and the difficulties encountered in conducting this project, I embarked on this venture because there is a key link between Merleau-Ponty's notion of animality and Deleuze's notion of meat, which demands our attention.

\section{Merleau-Ponty and Animalité | Between the Human Meat-the Animal Flesh}

The human, the animal, the non-human, the flesh, the meat, there is no precise border between them. What is fascinating about Merleau-Ponty's lecture notes on nature is that he takes up the issue of the distinction between human animals and non-human animals in depth. Nowhere-even as early as his first book, The Structure of Behavior ${ }^{12}$ — does he take up thematically the problem of animal difference as he does in his courses on nature. The Phenomenology of Perception makes peripheral gestures regarding non-human animals. As a further parenthetical remark, one of Merleau-Ponty's 1948 seven radio lectures ${ }^{13}$ sheds light on the relation of human animals and non-human animals. These lectures were delivered three years after the publication of the Phenomenology of Perception. The order and the names of the titles were decided by Merleau-Ponty. The fourth lecture-"Exploring the World of Perception: Animal Life"-criticizes the modern conception of non-human animals as machines. This lecture precedes 
the discussion on human animals, "Man Seen from the Outside." These tangential notes are provided to remind the reader that Merleau-Ponty has not forgotten the question of animal difference. It is very much of a concern of Merleau-Ponty, even when it is not thematized explicitly in his texts.

Before digressing into more tangential, parenthetical, and peripheral historical and textual marks and remarks, let us get back to our pivotal concerns. Merleau-Ponty engages in the issue of the distinction between the human animal and the non-human animal through the notion of animality (l'animalite). Merleau-Ponty plays upon the French word l'animalité, which has many significations: (1) "The characteristics or nature of an animal,"14 (2) "The animal instincts of humans as distinct from their spiritual nature,"15 or (3) "Animals considered as a group; the animal kingdom." kingdom is "A main classification of living organisms that includes all animals (i.e. even humans)." 17 In the world, there are non-human animals and human animals, but this distinction, according to Merleau-Ponty, is not a clear-cut one. As Merleau-Ponty argues, "What exists are not separated animals, but an inter-animality (inter-animalité)" (NCF, 189). The non-human animal cannot be distinguished from the human animal and vice versa because there is a blurred distinction between, on the one hand, the "animality in the subject" (NCF, 166) and on the other, the animality as "a collective animal" (NCF, 169). Inverting the traditional distinction between animals and humans_- that was based on the analysis of their intrinsic mental faculties_-Merleau-Ponty writes, "The differentiation of the animal is expressed in a clearer way in its exterior surface than in its interior organization" (NCF, 187). As MerleauPonty further explains in a different way in the second course, "Animality, the Human Body, and the Passage to Culture":

We do not have the right to consider the species as a sum of individuals exterior to one another. There are as many relations among animals of one species as there are internal relations among every part of the body of each animal. The fact that there is a relation between the exterior aspect of the animal and its capacity for vision seems to prove it: the animal sees according to whether it is visible. This leads back to the same philosophi- 
cal considerations. Just as earlier there was a perceptual relation before perception properly so-called, so too is there here a specular relation between animals [non-human and human]: each is the mirror of the other. This perceptual relation gives an ontological value back to the notion of species (NCF, 189, not Merleau-Ponty's italics).

And as Merleau-Ponty, in "The Intertwining-The Chiasm," remarks in a remarkably similar way:

There is vision, touch, when a certain visible, a certain tangible, turns back upon, the whole of the visible, the whole of the tangible, of which it is a part, or when suddenly it finds itself surrounded by them, or when between it and them, and through their commerce, is formed a Visibility, a Tangible in itself, which belong properly neither to the body qua fact nor to the world qua fact-as upon two mirrors facing one another where two indefinite series of images set in one another arise which belong really to neither of the two surfaces, since each is only the rejoinder of the other, and which therefore form a couple, a couple more real than either of them. Thus since the seer is caught up in what he sees, it is still himself he sees: there is a fundamental narcissism of all vision (VI, 139, long passage italics not Merleau-Ponty's).

The passages, "each is the mirror of the other" and "two mirrors facing one another where two indefinite series of images set in one another arise which belong really to neither of the two surfaces" are underscored and must be noted and annotated here. The non-human animal and the human animal are but mirrors to and for each other, one reflects the other and vice versa. The human animal, in other words, is to be understood through the nonhuman animal and the non-human animal is to be understood through the human animal and this can be done if what is between them is articulated, namely their ambiguity (l'ambiguité). As MerleauPonty questions, "Where are we to put the limit between the body and the world, since the world is flesh?" (VI, 138). I believe, the reason why, even as late as The Visible and the Invisible, MerleauPonty does not make a clear-cut separation between the meat of the non-human animal and the flesh of the human animal is be- 
cause flesh and meat are not two kinds of entities, but rather flesh is all there is and is not. And this ontological notion of flesh is what lies between the human animal flesh and bones and non-human animal meat. The human animal flesh is a "remarkable variant" of the non-human animal flesh and vice versa (VI, 136). As MerleauPonty accentuates, "It is by the flesh of the world that in the last analysis one can understand the lived body (corps propre)" (VI, 250). To incorporate the notion of meat in Merleau-Ponty's notion of flesh, it can be said, the human animal meat is a variant of the non-human animal meat and vice versa. The non-human animals, like the human animal lived bodies are sensible-sentient "variants" of the sensible flesh of the world.

I am vacillating between Nature and The Visible and the Invisible because they both, as aforementioned earlier, complement and supplement each other in their explanations through and through. The human animal cannot be thought of in separation from its nonhuman animal. As it is explicit also from the third course, "Nature and Logos: The Human Body": "Animality and human being are given only together" (NCF, 271). They both are variants of the same fabric, namely, flesh: "The Ineinander of animality-humanity = grasped in other living beings as variants" (NCF, 208). Animality, in human animals, must not be thought as a superimposable ingredient. As a side historical note, this is a clear repudiation of Aristotle's formulation of the human being in the Metaphysics as a "rational animal." The human animal cannot be simply divided into two compartments, rationality and animality. This is a form of reductionism to which Merleau-Ponty was against since The Structure of Behavior. As Merleau-Ponty boldly puts: the "human cannot appear in its qualitative difference by mere addition of reason to the animal (body)" (NCF, 214). The non-human animal is more than a bundle of meat and stimuli responses. Merleau-Ponty's description of the human animal as intertwined (Ineinander) with the non-human animal dismantles all traditional hierarchies between humans and animals. Animality and humanity are not abstract ideas, but each of them are, what Merleau-Ponty calls, a kind of "corporeity" (NCF, 208). And what connects and separates the human animal with the non-human animal and vice versa is not "reason" but their "corporeity." They are both intertwined within 
flesh with each other as flesh through each other's flesh. "The human," Merleau-Ponty goes on to say, is "to be taken in the Ineinander with animality and Nature. ... Reciprocally, human being is not animality (in the sense of mechanism) + reason. And this is why we are concerned with the body: before being reason, humanity is another corporeity" (NCF, 208).

A human animal is not a rational animal and a non-human animal is not an irrational animal or an animal without reason. This distinction, according to Merleau-Ponty, cannot hold any more. There is no hierarchy between a human animal and a non-human animal. Their relation is ambiguous. No one species is superior to another, even if one has rational capacity, while the other does not. Their ultimate difference lies not in their cognitive capacities, but in their corporeity. I stress this because the human only emerges "as different from the animal, not by addition of reason, but rather, in short, in the Ineinander with the animal [that is to say,] (strange anticipations or caricatures of the human in the animal)" (NCF, 214). Here, it must be highlighted that Merleau-Ponty draws our attention to where the kinship lies between the non-human animal and the human animal, namely, in the traces of their "caricatures" in each other: the hands, the face, the structure of the face, the organization of the organs, the number of fingers, hands, and legs and so on (NCF, 214). The corporeal features blur the clear-cut distinction between the human animal flesh and the non-human animal meat. The animality that separates the human animal and the non-human animal is what also clings them together. "From [all of] this follows," Merleau-Ponty concludes, "the relation of the human and animality is not a hierarchical relation, but lateral, an overcoming that does not abolish kinship" (NCF, 268).

\section{Towards Understanding Merleau-Ponty and Deleuze}

In retrospect, Merleau-Ponty's analysis of animal difference presented in the courses on nature marks him as a thinker who was ahead of his time. Even early as 1942, he was occupied with the problem of animal difference. Deleuze, after Merleau-Ponty, revisits the problem of animal difference through his notion of meat. For both Merleau-Ponty and Deleuze, the solution, for lack of a 
better word, to the traditional problem of animal difference lies in between the difference of animals and humans, rather than on either side of the difference. The difference, however, between their solutions lie in their philosophical notions. That is, MerleauPonty addresses the problem of animal difference through the ontological notion of flesh and animality, whereas Deleuze tackles it via the notions of meat and the zone of indiscernibility. Like MerleauPonty's notion of animality, Deleuze's notion of meat undoes any kind of hierarchy between flesh and bones and meat, on the one hand and human animals and non-human animals, on the other. The human (animal) becomes non-human (animal) and the (nonhuman) animal becomes (human) animal.

Even though Merleau-Ponty does not use the exact Deleuzean term, "l'viande," to question the distinction between the non-human animal and the human animal, he does so through the notion of "l'animalité," suggesting the Ineinander between human animals and non-human animals. Unlike Deleuze, Merleau-Ponty explicitly questions the traditional formulation of the human being as a "rational animal" and dismantles it by undoing the reductionism at work. But Deleuze, in contrast to Merleau-Ponty, creatively through Bacon's paintings articulates his notion of meat to interrupt the normal way of thinking about non-human animal meat and human animal flesh. These nuances between Merleau-Ponty and Deleuze are noteworthy because they inform the audience the differences between their interrogative approaches and their indefinite conclusions. But both thinkers are against any kind of arborescent structures or hierarchies.

What marks the difference between animals and humans are not their inner mental faculties but their outer corporeities, which leads to the ambiguity (l'ambiguite') and the indiscernibility (l'indiscernabilite) between the inside and the outside of, on the one hand, human animal flesh and non-human animal meat, and on the other hand, human animal meat and non-human animal flesh. At the end, I leave my audience with the problem of animal difference as a problem for further development and some words by Merleau-Ponty on the difference between the (human) animal [meat] and the (non-human) animal [flesh]: "The human and animal bodies are only homonyms" (NCF, 272). What are we to make 
of this weighty, fleshly, and meaty remark? It is a question that leads to another question, without a final answer, thus leaving the problem of animal difference open to further interpretation...

\section{Notes}

' Maurice Merleau-Ponty, The Visible and the Invisible: Followed by Working Notes, trans. Alphonso Lingis (Evanston: Northwestern University Press, 2000). Henceforth cited as VI.

${ }^{2}$ The American Heritage Dictionary, 3d., s.v. "flesh."

${ }^{3}$ Gilles Deleuze, Francis Bacon: The Logic of Sensation, trans. Daniel W. Smith (Minneapolis: University of Minnesota Press, 2003). Henceforth cited as FB.

${ }^{4}$ See Gilles Deleuze, "Becoming-Intense, Becoming-Animal, Becoming-Imperceptible...," A Thousand Plateaus: Capitalism and Schizophrenia, trans. Brian Massumi (Minneapolis: The University of Minnesota Press, 1987), 232-309.

${ }^{5}$ To see all, including these five, paintings of Francis Bacon and to read his biography, see Francis Bacon Image Gallery, <http:// www.francis-bacon.cx $>$ (19 November 2005).

${ }^{6}$ Bacon, "Three Studies of George Dyer, 1966," $<$ http://www. francisbacon.cx/portraits/dyer/gdy.html>.

${ }^{7}$ Bacon, "Study for Head of Lucian Freud, 1967," $<$ http://www. francisbacon.cx/portraits/freud/lucian67.html>.

${ }^{8}$ Bacon, "Three Studies for Portrait of Isabel Rawsthorne, 1968,"

$<$ http://www.francis-bacon.cx/portraits/isabel68.html >.

9 Bacon, "Three Studies for Henrietta Moraes, 1969,"

$<$ http://www.francis-bacon.cx/portraits/henrietta/moraes69.html $>$.

${ }^{10}$ Bacon, "Portrait of Michel Leiris," < http://www.francisbacon.cx/portraits/leiris/portrait 76.html >.

" Maurice Merleau-Ponty, Nature: Course Notes from the Collège de France, trans. Robert Vallier (Evanston: Northwestern University Press, 2003). Henceforth cited as NCF.

${ }^{12}$ Merleau-Ponty discusses animals in The Structure of Behavior, however, the question of animals is thought through behavior instead of human-animal intertwining. See Maurice Merleau-Ponty, "Higher Forms of Behavior," The Structure of Behavior, trans. Alden Fisher (Boston: Beacon Press, 1963), 93-128.

${ }^{13}$ Maurice Merleau-Ponty, "Exploring the World of Perception: Animal Life," The World of Perception, trans. Oliver Davis (London; New York: Routledge, 2004), 69-77. 
${ }^{14}$ The American Heritage Dictionary, 3d., s.v. "animality." ${ }^{15}$ Ibid.

${ }^{16}$ Ibid.

${ }^{17}$ The American Heritage Dictionary, 3d., s.v. "animal kingdom." 